\title{
A method of experimental studies of heat transfer processes between industrial constructions
}

\author{
Vadym Nizhnyk ${ }^{1, *}$, Oksana Kyrychenko, Olexandr Tarasenko ${ }^{3}$, Andrii Shvydenko, and \\ Serhii Hovalenkov ${ }^{3}$ \\ ${ }^{1}$ The Ukrainian Civil Protection Research Institute, 18, Rybalska St., Kyiv, 01011, Ukraine \\ ${ }^{2}$ Cherkasy Institute of Fire Safety named after Chornobyl Heroes of National University of Civil \\ Defense of Ukraine, 8, Onoprienko St.,Cherkasy, 18034, Ukraine \\ ${ }^{3}$ National University of Civil Defense of Ukraine, 94, Chernyshevska St., Kharkiv, 61023, Ukraine
}

\begin{abstract}
A method of experimental study of heat transfer processes between industrial constructions during a fire was developed. Types of equipment necessary for the conduction of the experimental studies were determined. A new type of specimen to be used as the one to be studied when conducting experimental studies was developed. Installation sites of thermocouples and heat flux detector on the specimen under study are shown as layout. Installation sites of the specimens under study relative to heat radiation source were substantiated experimentally. Succession of the conduction of the experimental studies of heat transfer processes between industrial constructions during a fire was developed which consists of the following procedures: production of specimens for the studies, measurement and recording on ambient conditions, measuring of temperature and heat flux on the surface of the specimen under study, and filling 55B test fire with water and diesel fuel. It was established that average temperatures and heat flux density values as well as flame geometry should be measured when performing experimental studies.
\end{abstract}

\section{Introduction}

Specific features of fires in industrial constructions, unlike buildings, lies in open burning without any flame restriction with non-combustible building constructions having some fire resistance class. This stipulates for more powerful effect of heat irradiation caused by fire due to larger area of flame on adjacent buildings and constructions.

Full-scale fire tests should be conducted to study the heat transfer processes between adjacent industrial constructions (one of which is burning and another one is being irradiated) in order to implement calculation method of the determination of fire breaks between manufacturing and industrial designation constructions. Essence of the method lies in the determination of heat flux density $\mathrm{q}_{2}\left(\mathrm{~kW} / \mathrm{m}^{2}\right)$ and temperature $\mathrm{T}_{2}\left({ }^{\circ} \mathrm{C}\right)$ at the surface of the object being irradiated (2) by flame (1) produced at the burning object (see Figure 1).

\footnotetext{
* Corresponding author: nignyk@ukr.net
} 


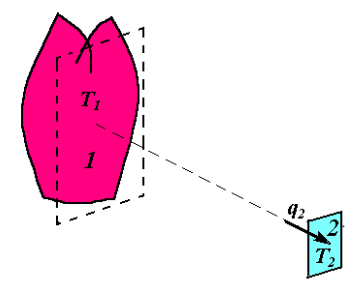

Fig. 1. Layout of item 2 irradiated by flame 1: 1 - surface of the flame reduced to rectangle; 2 surface of the object being irradiated; $r$ - distance between the planes of the rectangles.

\subsection{Literature review}

Analysis of relevant scientific papers showed that heat influence of fire was realized by heat transfer on account of radiative heat exchange [1 - 10]. This phenomenon shall be taken into account when substantiating fire breaks between buildings, too [9-12].

Classical theory of radiative heat exchange is laid down to the basis of substantiation of fire breaks between buildings. Essence of the tasks is reduced to the comparison of heat flux density irradiated by the facility being on fire qirr with maximum allowable heat flux density of the materials used at the irradiated facility qall, equation (1) [11].:

$$
\left(q_{\text {irr }} \leq 0.8 q_{\text {all }}\right) \mathrm{U}\left(\theta_{\text {irr }} \leq 0.8\left(\theta_{\text {all }}\right)\right.
$$

where $q_{\text {irr }}$ or $\theta_{\text {all }}$ - stands for heat flux density irradiated by the facility on fire; $q_{\text {all }}$ or $\theta_{\text {all }}$ stands for maximum allowable heat flux density for appropriate materials

\subsection{Purpose, objectives and results}

Object of this paper is the development of a method of experimental studies of heat transfer processes between adjacent facilities when simulating fire. The following tasks were to be solved in order to reach the object preset:

- to determine types of test equipment necessary for the experimental studies;

- to develop configuration of the specimen for studies;

- to substantiate points of placement of the specimens for studies relative to the heat radiation source;

- to develop sequence of conducting experimental studies.

Equipment used for the conduction of the full-scale fire experimental studies includes the following: class B test fire, specimen for studies, measuring instruments and equipment for photo and video shooting.

55B is used as test fire when performing studies in an industrial construction [13], this test fire represents metal pan $(1.480 \pm 0.5) \mathrm{mm}$ in diameter, height of its side board equals to $(150 \pm 5) \mathrm{mm}$ and thickness of the latter is $(2.5 \pm 0.5) \mathrm{mm}, 181$ of water and 371 of diesel fuel are poured into it.

The following measuring instruments were used in the course of the study:

- thermocouples;

- "Thermocount" measuring and calculating system;

- RAP-12M.2 thermal radiation receiver;

- heat flux meter;

- control unit;

- moisture gauge for wood;

- R10 UZK measuring tape;

- MV-4M aspiration hygrometer; 
- M67 aneroid barometer;

- ASO-3 winged anemometer;

- still and video cameras;

- Testo 885 infrared imager.

6 test specimens are used in the course of the studies.

We chose the following items in order to fabricate a specimen: 6 solid pine wood bars measuring $50 \mathrm{~mm} \times 50 \mathrm{~mm} \times 4,000 \mathrm{~mm}, 30$ solid pine wood boards measuring $20 \mathrm{~mm} \times 100 \mathrm{~mm} \times 700 \mathrm{~mm}, 12$ bars measuring $50 \mathrm{~mm} \times 50 \mathrm{~mm} \times 1.000 \mathrm{~mm}, 120$ nails measuring $4 \mathrm{~mm} \times 100 \mathrm{~mm}, 72$ nails measuring $2.5 \mathrm{~mm} \times 60 \mathrm{~mm}$, rotational processing machine and drying chamber.

Wood drying is done inside a drying chamber at the first stage of preparation until its moisture content decreases to $12 \%$ [12]. Its moisture content is measured by electric moisture gauge.

Interconnection of wood parts is performed at the second stage of preparation. Figure 2 shows layout of the specimen used for the study after interconnection of its constituent parts.

Some gaps are drilled at the specimen's surface in order to measure its surface temperature, this is done with a drill bit being $4 \mathrm{~mm}$ in diameter for the purpose of installation of the thermocouples (T1, T2, T3) according to the layout shown on Figure 2. Gap drilling is done in such a manner that thickness of the undrilled distance to the surface of the specimen is within 1 to $2 \mathrm{~mm}$; this ensures determination of the most exact data as to warming of the surface of the specimen under study.

Thermal radiation receiver is installed on the surface of the specimen (see Figure 2).

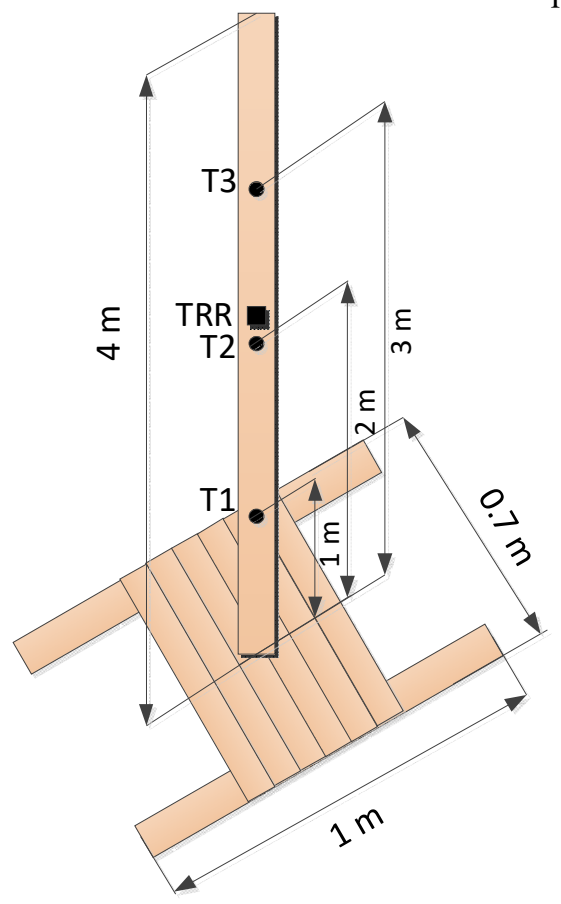

Fig. 2. Layout of the specimen under study (T1, T2, T3 stand for the places for the thermocouples installation, TRR stands for the place of the thermal radiation receiver installation).

Some trial experimental studies for the determination of temperature distribution during 55B test fire burning were conducted preliminarily for the purpose of substantiation of the places where the specimens under study shall be placed relative to heat radiation source. 
The test specimens are placed as per layout shown on Figure 3.

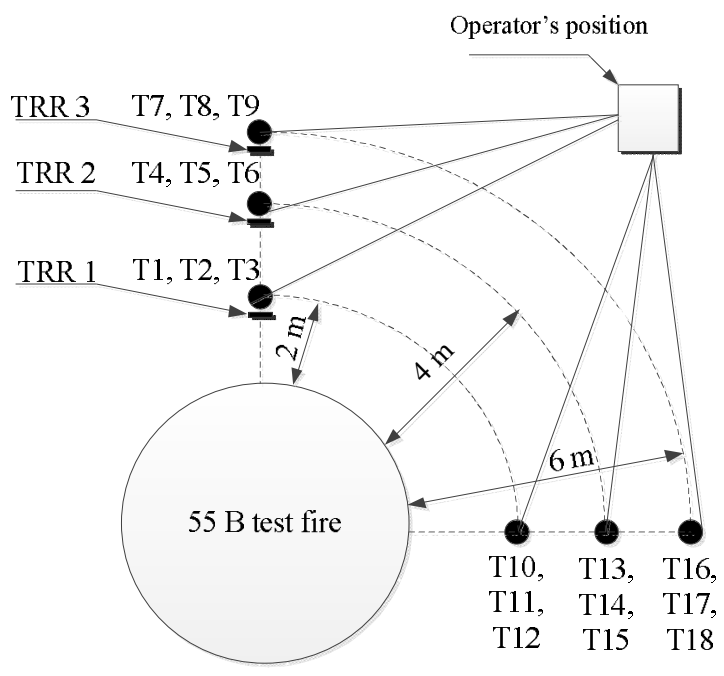

Fig. 3. Layout of the test specimens and measuring instruments installation (T1 to T18 stand for thermocouples, TRR1 to TRR 3 stand for thermal radiation receivers).

Temperatures versus duration of heat irradiation curves at various places relative to $55 \mathrm{~B}$ test fire are shown on Figure 4.

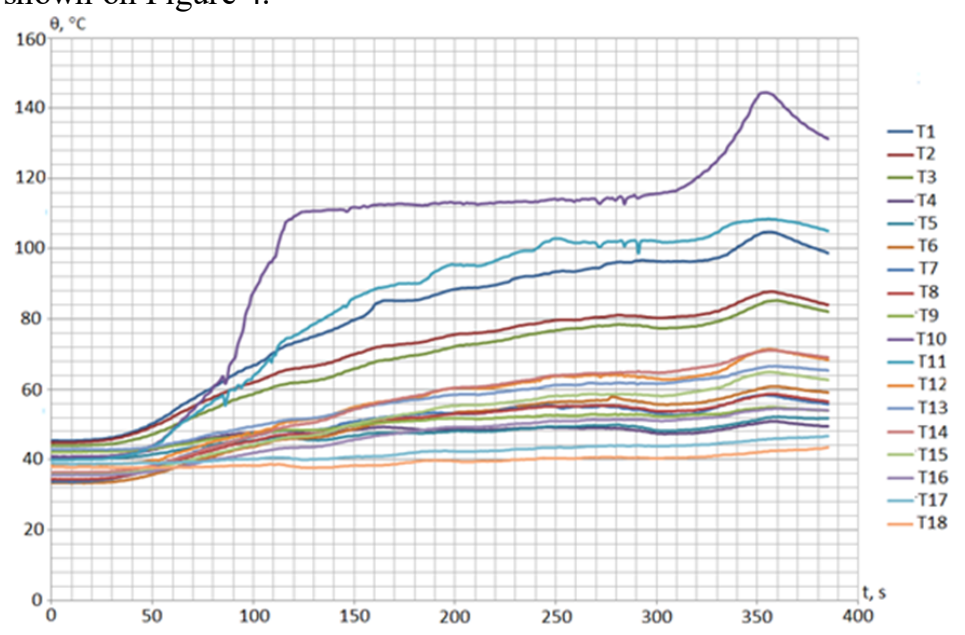

Fig. 4. Temperature versus duration of heat irradiation curves.

Thus, one can conclude that it is parts of the samples under study located 1 to $2 \mathrm{~m}$ above ground level that experience the most intensive heat irradiation. Temperature of the specimens' surface lowers as distance to 55B test fire increases.

Therefore when performing experimental studies of the heat transfer processes between industrial constructions thermocouples installation at the specimens under study shall be taken as 1, 2 and $3 \mathrm{~m}$; this case corresponds to maximum intensity of heat irradiation of the specimens under study caused by 55B test fire. At that we propose to place the specimens under study $2 \mathrm{~m}, 4 \mathrm{~m}$ and $6 \mathrm{~m}$ away from 55B test fire.

Experimental studies are conducted using at least three specimens under the following weather conditions: no atmospheric precipitations, air temperature $+5^{\circ} \mathrm{C}$ to $+40^{\circ} \mathrm{C}$, maximum wind velocity $3 \mathrm{~m} / \mathrm{s}$. 
We conduct experimental studies with the following sequence:

1. Preparation:

1.1 Fabrication of the specimens for studies.

1.2 Placement of 55B test fire at fire testing ground.

1.3 Positioning of the specimens and measuring instruments as per layout shown on Figure 3.

1.4 Installation of measuring instruments (thermocouples, heat radiation receivers) in accordance with the layout shown on Figure 2. The thermocouples are connected with the "Thermocount" information and measuring system, and heat radiation receivers as well as heat flux meter are checked for their proper operation.

1.5 Preparation of the equipment necessary for photo and video shooting.

1.6 Installation of Testo 885 thermal imager on the stand.

1.7 Preparation of appropriate first aid fire-fighting means.

2. Sequence:

2.1 Measuring and recording of the environmental conditions (air temperature, wind velocity, humidity and atmospheric pressure) are performed:

- air temperature and humidity are measured with MV-4M aspiration hygrometer;

- atmospheric pressure is measured with M 67 aneroid barometer;

- wind velocity is measured with ASO-3 winged anemometer

2.2 Measurement and recording of the initial values of temperatures and heat radiation are conducted.

2.3 55B test fire is filled with water and fuel no later than 3 minutes before starting the studies.

2.4 Information and measuring devices are switched to record mode and video shooting and thermal imager are triggered; 55B test fire is ignited.

2.5 Operations using thermal imager:

- accumulator battery is connected;

- objective lens cap is removed;

- memory card is installed\$

- thermal imager is switched on;

- basic adjustments are performed. Irradiation factor is set as per recommendations on the device operation in order to record temperatures more qualitatively (irradiation factor for wood equals to 0.74 );

- measurement results recording is started;

- device adjustment as well as changing its position relative to the specimens under study as well as heat radiation source are possible if necessary when conducting measurements;

- recorded data are saved upon cessation of the study and equipment being constituent parts of the device are packed.

2.6 When conducting studies using information and measuring system we measure and record temperature values at the exposed surface of the specimen under study as well as heat flux intensity at appropriate distances from the test fire. Temperature and heat flux recording is done at intervals not exceeding $1 \mathrm{~min}$. Video shooting is performed at the moment of the most intensive burning of the fire load. Photo and video shooting are done in order to determine flame geometrical parameters.

2.7 Studies are conducted until complete burning-out of the diesel fuel poured into 55B test fire.

3. Estimation:

3.1 Using results of the studies for each time moment tj when the measurement was taken we determine surface temperature of the specimen under study $\theta \mathrm{j}$ and heat flux 
density qj as well as geometrical parameters of the flame (hj, $\delta \mathrm{j})$. Experimental results are put down to the log of experimental studies.

3.2 Using results of the studies we calculate measuring error using the following formula:

$$
\Delta A= \pm k \sqrt{\left(\Delta A_{1}\right)^{2}+\left(\Delta A_{2}\right)^{2}}
$$

where $\Delta A$ - absolute error of the figures being measured;

$\triangle A_{1}$ - error of detectors (thermocouples, heat flux meter, and instrumental one);

$\Delta A_{2}$ - error of measuring devices ("Thermocount" information and measuring system, heat flux meter, and error of reading of the results when measuring dimensions);

$\kappa$ is a factor which depends on probability $(\mathrm{k}=1.1$ at $\mathrm{P}=0.95)$ [11].

When performing experimental studies we derive average temperature and heat flux values as well as flame geometrical parameters. Temperatures, heat flux and flame geometrical parameters versus time are plotted.

\section{Conclusions}

We proposed a method of experimental studies of heat transfer processes between adjacent constructions in this paper, and at that:

points of placement of the specimens for studies relative to heat flux source were substantiated experimentally and it was revealed that when conducting experimental studies of heat transfer processes between 55B test fire and specimens under study the highest heat irradiation of the specimen takes place at 1 to $2 \mathrm{~m}$ height;

sequence of conduction of experimental studies of heat transfer processes between adjacent facilities during fire was developed.

\section{References}

1. S. Pozdieiev, O. Nuianzin, S. Sidnei, S. Shchipets, MATEC Web of Conferences, 116, 02027 (2017).

2. O.Nekora, V. Slovynsky, S. Pozdieiev, MATEC Web of Conferences, 116, 02024 (2017).

3. K. Mygalenko, V. Nuyanzin, A. Zemlianskyi, A. Dominik, S. Pozdieiev, EasternEuropean Journal of Enterprise Technologies 1, 31-37 (2018).

4. Y. Danchenko, V. Andronov, M. Teslenko, V. Permiakov, E. Rybka, R. Meleshchenko, A. Kosse, Eastern European Journal of Enterprise Technologies 1, 9-17 (2018).

5. B. Pospelov, V. Andronov, E. Rybka, V. Popov, A. Romin, EasternEuropean Journal of Enterprise Technologies, 1, 50-55. (2018).

6. B. Pospelov, V. Andronov, E. Rybka, V. Popov, O. Semkiv, EasternEuropean Journal of Enterprise Technologies,10, 2 (2018).

7. B.V. Hrushevskiy, A.I. Yakovlev, I.A. Krivosheyev, Fire prevention in building industry, Moscow, 451, (1985).

8. M.Ya. Roitman., Ye.P. Komissarov., V.A.. Pchelintsev, Thermal dynamics and heat transfer in fire-fighting procedures, Moscow, 415, (1977)

9. P.N. Romanenko, Yu.A. Koshmarov, M.P. Bashkirtsev, Fire prevention in building industry, Moscow, 363, (1978).

10. Morgan J. Hurley, SFPE Handbook of fire protection engineering, Greenbelt, 351, (2016). 
11. GOST 12.1.004-91 Fire and explosion safety of substances and materials and methods of their determination, (1996).

12. DSTU-N B EN 1995-1-2:2012 Eurocode 5. Designing of wood constructions. Part 1-2. General regulations. Calculation of fire resistance of the constructions (EN 1995-12:2004, IDT), (2013).

13. DSTU 3675-98 Fire-fighting equipment. Portable fire extinguishers. General technical requirements and test methods, (1999). 